\title{
MEASURING SUBMICRON-SIZE FRACTIONATED PARTICULATE MATTER ON ALUMINUM IMPACTOR DISKS
}

\author{
Bruce A Buchholz ${ }^{1,2}$ • Paula Zermeño ${ }^{1}$ • Hyun-Min Hwang ${ }^{3}$ Thomas M Young • $^{3}$ \\ Thomas P Guilderson ${ }^{1}$
}

\begin{abstract}
Submicron-sized airborne particulate matter (PM) is not collected well on regular quartz or glass fiber filter papers. We used a micro-orifice uniform deposit impactor (MOUDI) to fractionate PM into 6 size fractions and deposit it on specially designed high-purity thin aluminum disks. The MOUDI separated PM into fractions 56-100, 100-180, 180-320, $320-560,560-1000$, and 1000-1800 $\mathrm{nm}$. Since the MOUDI has a low flow rate ( $30 \mathrm{~L} / \mathrm{min})$, it takes several days to collect sufficient carbon on 47-mm foil disks. The small carbon mass (20-200 $\mu \mathrm{g} \mathrm{C})$ and large aluminum substrate ( $25 \mathrm{mg} \mathrm{Al})$ present several challenges to production of graphite targets for accelerator mass spectrometry (AMS) analysis. The Al foil consumes large amounts of oxygen as it is heated and tends to melt into quartz combustion tubes, causing gas leaks. We describe sample processing techniques to reliably produce graphitic targets for ${ }^{14} \mathrm{C}$ AMS analysis of $\mathrm{PM}$ deposited on $\mathrm{Al}$ impact foils.
\end{abstract}

\section{INTRODUCTION}

Atmospheric particulate matter (PM) is a complex mixture of small particles and liquid droplets in the air produced by natural phenomena and anthropogenic activities. These particles vary in size from nanometers to tens of microns and adversely impact public health and visibility, and produce radiative forcing effects on global climate. Exposure to particulate matter in ambient air, particularly submicron particles inhaled deep into the lungs, has been linked to increased aggravated asthma, premature death in people with heart and lung disease, and hospital admission for cardiovascular and respiratory diseases in many urban areas (Pope and Dockery 2006; Dockery 2009).

To protect public health and welfare, the United States Environmental Protection Agency (USEPA) promulgated national ambient air quality standards (NAAQS) for $\mathrm{PM}_{10}$ (aerodynamic diameter $\leq 10 \mu \mathrm{m}$ ) in 1987 and for $\mathrm{PM}_{2.5}$ (aerodynamic diameter $\leq 2.5 \mu \mathrm{m}$ ) in 1997. These NAAQS established exposure limits for $\mathrm{PM}_{10}$ in 1987 at $150 \mu \mathrm{g} / \mathrm{m}^{3}$ for a 24-hr average and $50 \mu \mathrm{g} / \mathrm{m}^{3}$ for an annual average, and limits for $\mathrm{PM}_{2.5}$ in 1997 at $65 \mu \mathrm{g} / \mathrm{m}^{3}$ for a 24-hr average and $15 \mu \mathrm{g} / \mathrm{m}^{3}$ for an annual average. USEPA revised the NAAQS PM standard in 2006 (USEPA 2006), reducing the 24-hr average $\mathrm{PM}_{2.5}$ standard from 65 to $35 \mu \mathrm{g} / \mathrm{m}^{3}$ while retaining the annual average $\mathrm{PM}_{2.5}$ standard and 24-hr average $\mathrm{PM}_{10}$ standard. The state of California has set a lower annual average $\mathrm{PM}_{2.5}$ standard of $12 \mu \mathrm{g} / \mathrm{m}^{3}$.

The size distribution of anthropogenically produced particles from many combustion sources has changed dramatically over the past 3 decades. The earliest vehicle emission standards regulated PM mass/distance driven without any constraint on the size of the particles. It was clear that relatively few large particles dominated these measurements. As vehicle and fixed combustion source PM emission standards tightened over this period, emission control technology effectively reduced PM mass emitted. The largest particles responsible for most of the mass were easiest to capture and their elimination reduced mass most dramatically. Unfortunately, the emission controls that enabled combustion sources to meet the regulations also produced many more smaller and ultrafine $(<100 \mathrm{~nm})$ particles (USEPA 2004; Seigneur 2009). The recent switch to ultralow sulfur diesel fuel seems to have reduced the number of particles $<30 \mathrm{~nm}$ but has not changed PM mass (Ristovski et al. 2006).

\footnotetext{
${ }^{1}$ Center for Accelerator Mass Spectrometry, Lawrence Livermore National Laboratory, P.O. Box 808, Livermore, California 94551, USA.

${ }^{2}$ Corresponding author. Email: buchholz2@llnl.gov.

${ }^{3}$ Department of Civil and Environmental Engineering, University of California at Davis, One Shields Avenue, Davis, California 95616, USA.
}

(C) 2010 by the Arizona Board of Regents on behalf of the University of Arizona Proceedings of the 20th International Radiocarbon Conference, edited by A J T Jull RADIOCARBON, Vol 52, Nr 2-3, 2010, p 278-285 
A simple 2-component source model (fossil or biogenic carbon) often addresses the isotopic signatures of the dominant carbon sources of PM. The fossil contribution is produced primarily from fossil fuel combustion, most commonly assigned to diesel engines and large stationary sources such as coal-fired power plants. The biogenic contribution is a mixture of natural processes and anthropogenic activities. Residential wood burning and food cooking produce high levels of PM with carbon that generally was removed from the atmosphere within the past 100 yr. Previous studies have shown significant biogenic carbon in $\mathrm{PM}_{2.5}$ from natural sources (Lewis et al. 2004; Kleindienst et al. 2007). Our interest in examining the ${ }^{14} \mathrm{C} / \mathrm{C}$ signature of submicron $\mathrm{PM}$ is to determine if there is a dominant source of these particles and to provide real data for air quality regulators.

Capturing the submicron-sized PM of interest for radiocarbon analyses requires a non-traditional collection system. Standard high-volume air samplers typically collect $\mathrm{PM}_{10}$ or $\mathrm{PM}_{2.5}$ on quartz or glass fiber filters. Glass fiber and quartz filters are efficient collectors of these relatively large particles, but are less effective for ultrafines. Simultaneous separation of ultrafines into multiple size ranges depends on delicate aerodynamic flow, and the rough surfaces of quartz and glass fiber disrupt airflow. We used a micro-orifice uniform deposit impactor (MOUDI) to size fractionate particulate matter (PM) into 6 size fractions (56-100, 100-180, 180-320, 320-560, 560-1000, and 1000$1800 \mathrm{~nm}$ ) and deposit them on specially designed high-purity thin aluminum impactor disks, which optimize particle capture. These disks are not filters, the PM is physically implanted onto foil disks. Glass fiber and quartz filters do not work properly in MOUDI because the relatively rough surface of the filters produces too much turbulence.

PM ranging from ultrafines to $2 \mu \mathrm{m}$ collected on $\mathrm{Al}$ impactor disks or strips are not typically analyzed for ${ }^{14} \mathrm{C}$ content. MOUDI impactor disks ( $\mathrm{Al}$ or Teflon ${ }^{\circledR}$ ) are typically analyzed to identify metals or organic compounds in these tiny particles (Geller et al. 2005; Robert et al. 2007a,b; Kleeman et al. 2008, 2009; Krudysz et al. 2008). MOUDI samplers have multiple stages with small orifices and are operated with low flow rates, typically around $30 \mathrm{~L} / \mathrm{min}$, compared to high-volume samplers with flow rates $>1000 \mathrm{~L} / \mathrm{min}$. Consequently, MOUDI samplers needed to operate continuously for multiple days to deposit sufficient carbon mass for ${ }^{14} \mathrm{C}$ analyses.

Beyond the long collection times required, ${ }^{14} \mathrm{C}$ analyses of $\mathrm{Al}$ impactor strips also present challenges in sample preparation and graphite production. Despite the long collection times, most samples contained only 20-50 $\mu \mathrm{g} \mathrm{C}$ embedded in $25 \mathrm{mg}$ of Al. The Al foil consumes large amounts of oxygen during sample combustion and the tips of the $\mathrm{Al}$ tend to melt into the quartz combustion tubes, causing leaks. We used a pilot collection study as an example of the challenges a set of MOUDI foil disks presents for ${ }^{14} \mathrm{C}$ analysis. We describe sample processing techniques to reliably produce graphite targets for ${ }^{14} \mathrm{C}$ accelerator mass spectrometry (AMS) analysis of PM deposited on $\mathrm{Al}$ impactor disks.

\section{MATERIALS AND METHODS}

\section{Sampling Site and Collection}

The sampling site for this study was the rooftop of a gymnasium at an elementary school in a residential neighborhood in Sacramento, California, USA (see Figure 1). The rooftop is about $10 \mathrm{~m}$ above the ground surface and $2.5 \mathrm{~km}$ from a major interstate freeway.

Before sample collection, the MOUDI samplers were cleaned using tap water, methanol, and hexane in the laboratory to avoid any possible contamination. Aluminum foil impactor disks for the MOUDI samplers were precombusted at $450{ }^{\circ} \mathrm{C}$ for $4 \mathrm{hr}$ and weighed using a microbalance. Preweighed 47-mm-diameter aluminum disks were installed on each MOUDI plate in the laboratory and then transported to the sampling site. 


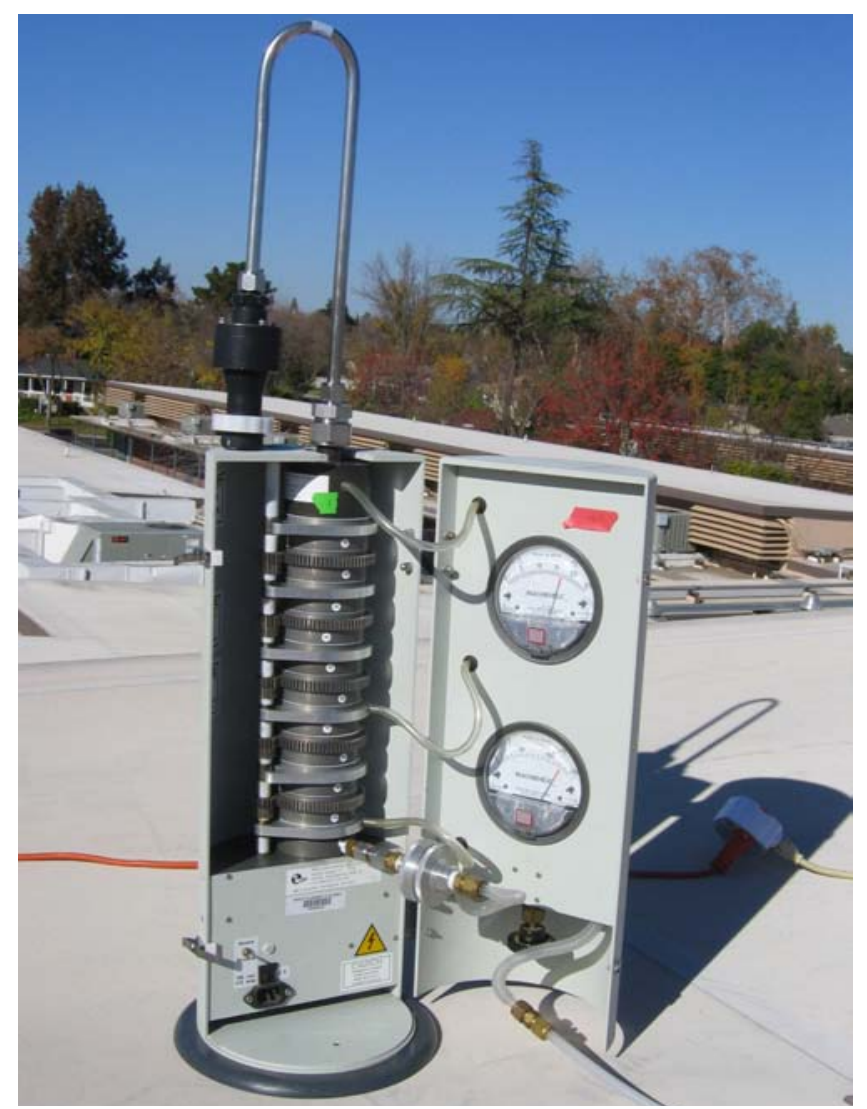

Figure 1 MOUDI sampler atop school gymnasium during sample collection

The MOUDI samplers used in this study were originally designed to collect atmospheric PM with aerodynamic diameters ranging from $56 \mathrm{~nm}$ to $18 \mu \mathrm{m}$ in 11 different size ranges. They were modified to remove PM larger than $1800 \mathrm{~nm}$ using cyclones attached to inlets of the MOUDI samplers and collected 6 size ranges: 56-100, 100-180, 180-320, 320-560, 560-1000, and 1000-1800 nm. The cyclones mounted to the inlet of the MOUDI were designed to remove particles bigger than $1800 \mathrm{~nm}$. When the direction of the streamline of pumped air having a specifically determined flow rate changed tangentially, bigger particles could not stay in the stream of the air because they had greater internal momentum that led them to collide into the wall inside of the cyclone. The vast majority of these bounced particles did not re-enter the stream of the air; instead, they settled to the bottom of the cyclone by gravity. The flow rate was $30 \mathrm{~L} / \mathrm{min}$. Pilot samples were collected during the early winter when dust levels were relatively high. Sampling spanned multiple days to acquire a sufficient mass of carbon for ${ }^{14} \mathrm{C}$ analysis.

After collection, loaded aluminum foil disks were transported to the laboratory intact in the MOUDI samplers and removed from each plate and individually placed in petri dishes lined with aluminum foil. A loaded foil disk is shown in Figure 2. All petri dishes were sealed with Teflon tape and stored in a freezer $\left(-20^{\circ} \mathrm{C}\right)$. Loaded disks were transferred by ground transportation from UC-Davis to Lawrence Livermore National Laboratory for ${ }^{14} \mathrm{C}$ analysis. 


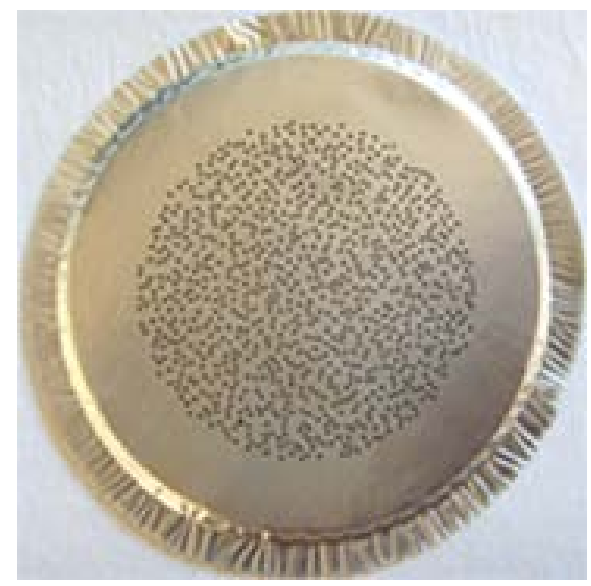

Figure 2 Loaded 47-mm foil impactor disk for PM $180-320 \mathrm{~nm}$.

\section{AMS Sample Preparation}

The loaded foil disks and control blank disks were cut into thin strips ( 3 $\mathrm{mm})$ for placement in 6mm-OD quartz combustion tubes. The foil strips were pushed into the quartz tube with a stainless steel rod and $\mathrm{CuO}$ was added after every 2 or 3 strips. Care was taken to avoid forming an impermeable plug of foil when packing with the rod. The distribution of $\mathrm{CuO}$ oxidizer between strips insured oxygen throughout the tube in case of accidental production of a foil plug. The 6-mm quartz tube loaded with foil and $\mathrm{CuO}$ required double-tubing by placing it inside a 10-mm-OD quartz tube for combustion (Figure 3a). This was required because the points at which the tips and edges of the $\mathrm{Al}$ foil touched the quartz surface caused the foil to melt and compromise the integrity of the quartz, causing gas leaks. By double-tubing, if the inner tube was damaged by the foil melts, the outer tube remained intact. The combustion of the foil yielded a gossamer film aside from the melts at the tips (Figure $3 \mathrm{~b}$ ). Each sample contained $600-800 \mathrm{mg}$ of $\mathrm{CuO}$ to ensure sufficient oxygen to oxidize both the 25-mg Al foil and the 20-200 $\mu \mathrm{g}$ C.

a

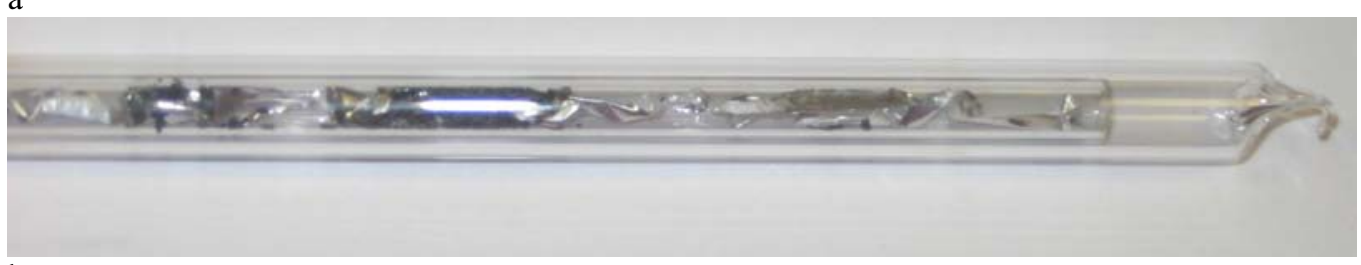

$\mathrm{b}$

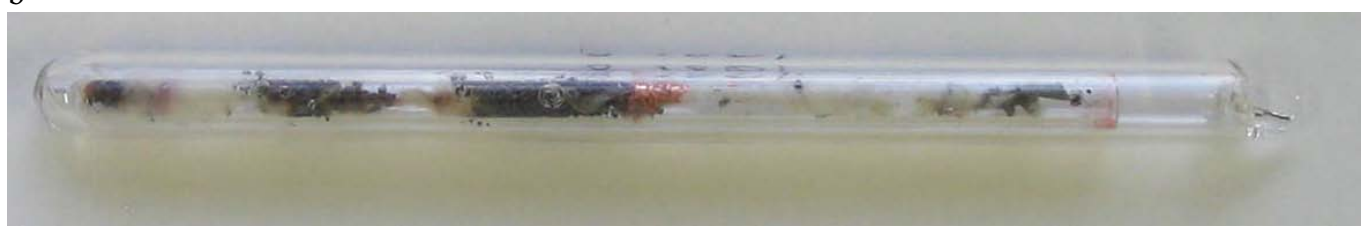

Figure 3 MOUDI foil sample packaged in quartz double-tube before (a) and after (b) combustion. 
All samples and controls were prepared in the LLNL Natural Carbon Preparation Laboratory using established methods. The quartz tubes were evacuated, sealed with a $\mathrm{H}_{2} / \mathrm{O}_{2}$ torch, and heated to $900{ }^{\circ} \mathrm{C}$ for $3.5 \mathrm{hr}$ to oxidize all carbon to $\mathrm{CO}_{2}$. After each quartz sample tube cooled to room temperature, it was placed in a flexible, evacuated chamber and broken to release the combustion gases. The evolved $\mathrm{CO}_{2}$ was purified, trapped, and reduced to graphite in the presence of iron catalyst in individual reactors (Vogel et al. 1987; Santos et al. 2004). All ${ }^{14} \mathrm{C} / \mathrm{C}$ measurements were completed with graphite targets analyzed at the Center for Accelerator Mass Spectrometry at Lawrence Livermore National Laboratory on the HVEE FN-class tandem electrostatic AMS system.

Blank foil disks were packaged as described above but contained too little carbon $(1 \mu \mathrm{g})$ to produce a viable AMS sample. Blank disks were then combusted with small measured samples (20-50 $\mu$ g C) of NIST 4990C oxalic acid or the ${ }^{14} \mathrm{C}$-free fullerene soot we use in aerosol monitors (Buchholz et al. 2000) to assess fossil and contemporary carbon contributions, respectively, to the background (Brown and Southon 1997). Double-tubed, small measured samples of NIST 4990C oxalic acid and ${ }^{14} \mathrm{C}$-free fullerene soot were also combusted without the aluminum disks but with large amounts of $\mathrm{CuO}$. The foil disks did not contain any additional contaminating carbon. The addition of the foil to the small (20-50 $\mu \mathrm{g} \mathrm{C)} \mathrm{oxalic} \mathrm{acid} \mathrm{and} \mathrm{fullerene} \mathrm{soot} \mathrm{samples} \mathrm{did} \mathrm{not} \mathrm{shift} \mathrm{isotope} \mathrm{ratios} \mathrm{or} \mathrm{increase}$ $\mathrm{CO}_{2}$ pressure post combustion. Backgrounds were attributable to double-tube combustion with very large amounts of $\mathrm{CuO}$.

We used a $\delta^{13} \mathrm{C}$ correction of $-25 \pm 2 \%$ for all samples based on measurement of selected sample splits of $\mathrm{PM}_{2.5}$ samples collected concurrently. Corrections for background contamination introduced during sample preparation were made following the procedures of Brown and Southon (1997). All data were normalized with 6 identically prepared NIST SRM 4990B (oxalic acid I) standards. We used NIST SRM 4990C (oxalic acid II), ANU sucrose, and TIRI wood (Scott 2003) as quality controls to monitor spectrometer performance. The measurement error was determined for each sample and ranged between \pm 2 to $10 \%$ o $(1 \sigma)$.

The text reports ${ }^{14} \mathrm{C} / \mathrm{C}$ concentrations in $\mathrm{F}^{14} \mathrm{C}$ units (fraction modern) using the nomenclature of Reimer et al. (2004). We avoid the percent modern carbon (pMC) nomenclature due to its inconsistent use in the literature.

\section{RESULTS AND DISCUSSION}

The particulate matter (PM) $<1 \mu \mathrm{m}$ had high carbon content, typically on the order of $75 \% \mathrm{C}$ by mass (Figure 4). Still, the 1000-1800 nm fraction had significant mineral content. These carbon masses are useful when assessing whether multiple MOUDI disks are needed to obtain sufficient carbon for graphite production and measurement.

${ }^{14} \mathrm{C}$ concentrations of the size-fractionated PM varied with particle size over a relatively narrow range (Figure 5). The PM was attributed to either fossil or biogenic carbon sources through its ${ }^{14} \mathrm{C}$ concentration. There are obviously more than 2 carbon sources, but a simple 2-component source model addresses the isotopic signatures of major carbon sources. The fossil contribution is produced primarily from fossil fuel combustion, most commonly assigned to diesel engines and large stationary sources. The biogenic contribution is a mixture of natural processes and anthropogenic activities. Residential wood burning produces high levels of PM with carbon that generally was removed from the atmosphere in the past $5-100$ yr. Assigning a ${ }^{14} \mathrm{C} / \mathrm{C}$ value for biogenic carbon requires estimating the age of wood used for residential wood burning. This value will vary with location and the source of firewood. In the case of forest fires, much of the biomass consumed consists of ground cover, brush, and leaves grown over the past few years (Bench 2004). 


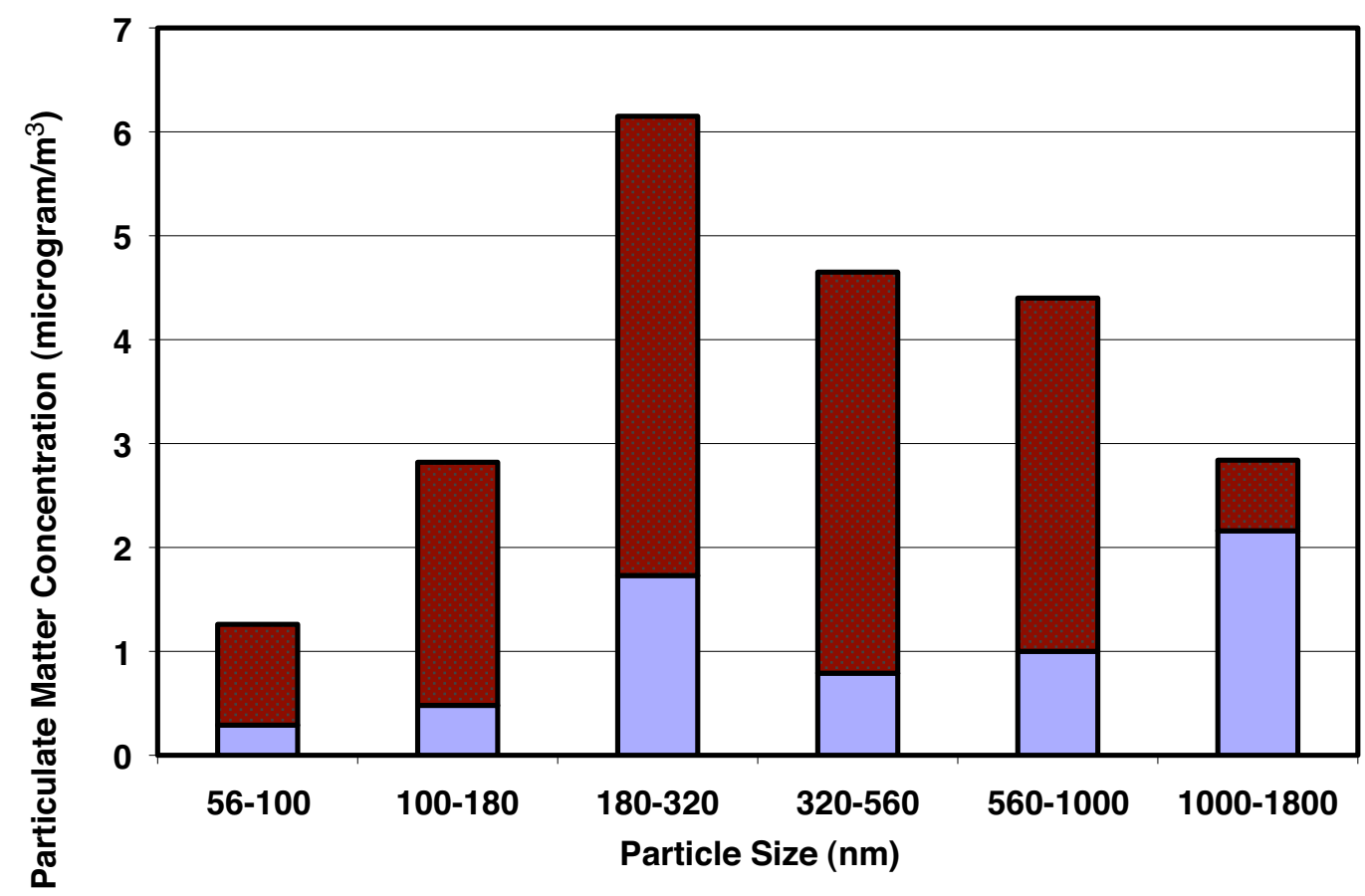

Don-carbon Concentration $\quad$ Carbon Concentration

Figure 4 PM loading on MOUDI disks in mass deposited per $\mathrm{m}^{3}$ of air flow

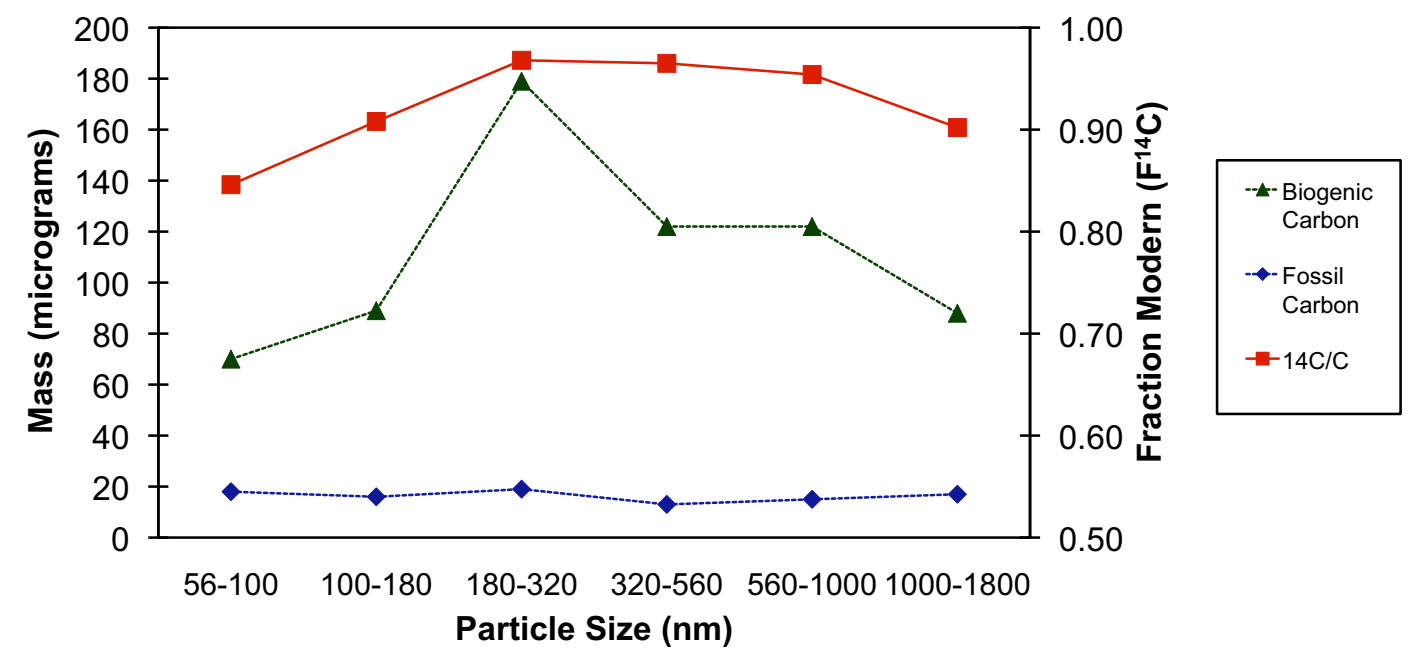

Figure 5 Contributions of fossil and biogenic carbon to size-fractionated PM. The mass of the fossil carbon contribution changed little among the different size fractions. The varied mass of the biogenic carbon among size fractions produced the variation in measured ${ }^{14} \mathrm{C} / \mathrm{C}$. Error bars are smaller than the symbols. 
With the measurement of total carbon mass $\left(m_{T}\right)$ for every size fraction, the mass of biogenic $\left(m_{B}\right)$ and fossil $\left(m_{F}\right)$ carbon is given by

$$
m_{B}+m_{F}=m_{T}
$$

The ${ }^{14} \mathrm{C}$ of each component is the product of the mass $\left(m_{i}\right)$ and measured isotopic ratio $\left(R_{i}\right)$ of that component. The total ${ }^{14} \mathrm{C}$ is the sum of the parts:

$$
R_{T} m_{T}=R_{F} m_{F}+R_{B} m_{B}
$$

Equation 1 can be substituted into Equation 2 and solved for $m_{F}$ in terms of the measured quantities $m_{T}, R_{T}$, and assumed values for $R_{B}$ and $R_{F}$. One can then solve for $m_{B}$. We used a value of $R_{B}$ equivalent to $\mathrm{F}^{14} \mathrm{C}=1.07$ when the atmosphere was about $\mathrm{F}^{14} \mathrm{C}=1.05$ to account for the difference between contemporary atmosphere and combusted biogenic sources. We used a value of $R_{F}$ equivalent to $\mathrm{F}^{14} \mathrm{C}=0.001$ to reflect that it is basically instrumental background.

The contributions of fossil and contemporary background carbon for these samples were measured using the technique of Brown and Southon (1997) at $2.0 \pm 0.5$ and $2.5 \pm 0.5 \mu \mathrm{g} \mathrm{C}$, respectively, for a double-tubed sample possessing 80-200 $\mu \mathrm{g}$ C. These values are consistent for double-tube samples with large amounts of $\mathrm{CuO}$. Only 1 foil can be placed inside the inner quartz combustion tube. When carbon loading on a foil is $<20 \mu \mathrm{g} \mathrm{C}$, multiple foil disks of the same size bin collected from MOUDI samplers operating in parallel can be combusted individually and the $\mathrm{CO}_{2}$ combined to produce a single graphite sample. The contributions of fossil and contemporary carbon for 2 doubletube samples were measured at $4.0 \pm 1.0$ and $5.0 \pm 1.0 \mu \mathrm{g} \mathrm{C}$, respectively. No extraneous $\mathrm{C}$ was added due to the process of combining $\mathrm{CO}_{2}$ from independent combustions. None of the samples reported here were so small to require concurrent disk addition for ${ }^{14} \mathrm{C}$ analysis.

Figure 5 plots the fossil and biogenic mass contributions for each size fraction. The fossil carbon contribution was relatively uniform across the size fractions examined. The differences in mass loadings were due to variations in biogenic carbon among the size fractions.

\section{CONCLUSION}

MOUDI Al foil disks are amenable to ${ }^{14} \mathrm{C} / \mathrm{C}$ analyses to provide fossil and biogenic carbon contributions in submicron size-fractionated PM. The Al foil impactor disks used in MOUDI samplers require customized sample processing to ensure reliable graphite production. Double-tube combustion is required to prevent tube failure and $\mathrm{CuO}$ must be sufficient for combustion of the foil disks. The foil disks contain very low levels of carbon, making background quantitation relatively easy. Double-tube combustion, high levels of $\mathrm{CuO}$ to combust the $\mathrm{Al}$ foil, and the need for multiple combustion tubes to acquire PM from multiple disks all raise backgrounds from typical samples. Background samples should be blank foils with ${ }^{14} \mathrm{C}$-free material scaled to the unknown sample masses.

\section{ACKNOWLEDGMENTS}

Work was supported by the California Air Resources Board under contract 06-339 and by Grant Number P42ES004699 from the National Institute of Environmental Health Sciences. The content is solely the responsibility of the authors and does not necessarily represent the official views of the National Institute of Environmental Health Sciences or the National Institutes of Health. This work was performed in part under the auspices of the US Department of Energy by Lawrence Livermore National Laboratory under Contract DE-AC52-07NA27344. 


\section{REFERENCES}

Bench G. 2004. Measurement of contemporary and fossil carbon contents of $\mathrm{PM}_{2.5}$ aerosols: results from Turtleback Dome, Yosemite National Park. Environmental Science \& Technology 38(8):2424-7.

Brown TA, Southon JR. 1997. Corrections for contamination background in AMS ${ }^{14} \mathrm{C}$ measurements. $\mathrm{Nu}$ clear Instruments and Methods in Physics Research B 123(1-4):208-13.

Buchholz BA, Freeman SPHT, Haack KW, Vogel JS. 2000. Tips and traps in the ${ }^{14} \mathrm{C}$ bio-AMS preparation laboratory. Nuclear Instruments and Methods in Physics Research B 172(1-4):404-8.

Dockery DW. 2009. Health effects of particulate air pollution. Annals of Epidemiology 19(4):257-63.

Geller VD, Sardar SB, Phuleria H, Fine PN, Sioutas C. 2005. Measurements of particle number and mass concentrations and size distributions in a tunnel environment. Environmental Science \& Technology 39(22):8653-63.

Kleeman MJ, Riddle SG, Jakober CA. 2008. Size distribution of particle-phase molecular markers during a severe winter pollution episode. Environmental Science \& Technology 42(17):6469-75.

Kleeman MJ, Riddle SG, Robert MA, Jakober CA, Fine PM, Hays MD, Schauer JJ, Hannigan MP. 2009. Source apportionment of fine $\left(\mathrm{PM}_{1.8}\right)$ and ultrafine $\left(\mathrm{PM}_{0.1}\right)$ airborne particulate matter during a severe winter pollution episode. Environmental Science \& Technology 43(2):272-9.

Kleindienst TE, Jaoul M, Lewandowski M, Offenberg JH, Lewis CW, Bhave PV, Edney EO. 2007. Estimates of the contributions of biogenic and anthropogenic hydroarbons to secondary organic aerosol at a southeastern US location. Atmospheric Environment 41(37): 8288-300.

Krudysz MA, Froines JR, Fine PM, Sioutas C. 2008. Intra-community spatial variation of size-fractionated PM mass, OC, EC, and trace elements in the Long Beach, CA area. Atmospheric Environment 42(21): 5374-89.

Lewis CW, Klouda GA, Ellenson WD. 2004. Radiocarbon measurement of the biogenic contribution to summertime PM-2.5 ambient aerosol in Nashville, TN. Atmospheric Environment 38(35):6053-61.

Pope CA, Dockery DW. 2006. Health effects of fine particulate air pollution: lines that connect. Journal of the Air \& Waste Management Association 56(6):709-42.
Reimer PJ, Brown TA, Reimer RW. 2004. Discussion: reporting and calibration of post-bomb ${ }^{14} \mathrm{C}$ data. Radiocarbon 46(3):1299-304.

Ristovski ZD, Jayaratne ER, Lim M, Ayoko GA, Morawska L. 2006. Influence of diesel fuel sulfur on nanoparticle emissions from city buses. Journal of the Air \& Waste Management Association 40(4):1314-20.

Robert MA, Van Bergen S, Kleeman MJ, Jakober CA. 2007a. Size and composition distributions of particulate matter emissions: part 1-light-duty gasoline vehicles. Journal of the Air \& Waste Management Association 57(12):1414-28.

Robert MA, VanBergen S, Kleeman MJ, Jakober CA. 2007b. Size and composition distributions of particulate matter emissions: part 2-heavy-duty diesel vehicles. Journal of the Air \& Waste Management Association 57(12):1429-38.

Santos GM, Southon JR, Druffel-Rodriguez K, Griffin S, Mazon M. 2004. Magnesium perchlorate as an alternative water trap in AMS graphite sample preparation: a report on sample preparation at KCCAMS at the University of California, Irvine. Radiocarbon 46(1): 165-73.

Scott EM. 2003. The Third International Radiocarbon Intercomparison (TIRI) and the Fourth International Radiocarbon Intercomparison (FIRI), 1990-2002: results, analyses, and conclusions. Radiocarbon 45(2): 135-408.

Seigneur C. 2009. Current understanding of ultrafine particulate matter emitted from mobile sources. Journal of the Air \& Waste Management Association 59(1):317.

USEPA (United States Environmental Protection Agency). 2004. The Particle Pollution Report: Current Understanding of Air Quality and Emissions through 2003. EPA 454-R-04-002. Research Triangle Park: Monitoring and Analysis Division, Office of Air Quality Planning and Standards Emissions.

USEPA (United States Environmental Protection Agency). 2006. Revisions to ambient air monitoring regulations; final rule. Federal Register 71(200): 61,236-328.

Vogel JS, Southon JR, Nelson DE. 1987. Catalyst and binder effects in the use of filamentous graphite for AMS. Nuclear Instruments and Methods in Physics Research B 29(1-2):50-6. 